\section{Who is Phoenix?}

\author{
Roberto D'Angelo
}

"Some patients find it difficult to be in the present because they are stuck in the past; others, by contrast, struggle to remain connected with the past and are suspended in a so-called present that is effectively atemporal, that is out of time". ${ }^{1}$ (p.360)

For psychoanalysts, the most profound and ultimately ethical way that we can help individuals, is by helping them know themselves. This involves discovering how they were shaped by their past and how their ongoing self-experience cannot be understood in isolation from its constitutive contexts. Psychoanalysts help patients explore foundational questions such as: 'Who am I?' 'How did I get here?' 'How am I implicated in my own suffering?' 'How can I grow and flourish and truly engage with my life?'. The answers to these questions emerge from a detailed exploration of the persons lived relational history, their current social and relational context and the political systems within which they are embedded. It is via this expansion of self-awareness that individuals can access agency and true freedom of choice.

The clinical approach presented by Notini et $a l^{2}$ is grounded in a completely different, radically decontextualised understanding of human experience. Their conceptualisation of Phoenix's gender identity is ahistorical and atemporal: it is indeed 'out of time'. For these authors, gender identity is assumed to be an immutable core essence, much like Ehrensaft's ${ }^{3}$ (p.341) 'true gender self.... there from birth'. It simply 'is'. This is a politically charged assumption, as we still have no established model for how gender identity/variance develops. The model that Notini et al privilege is in essence a biological one (see Fausto Stirling $^{4}$ ), which remains unsubstantiated. This model locates the problem within the individual body/mind and therefore the solution involves correcting the identity-body mismatch. Phoenix's social and relational context only has relevance insofar as it is supportive or rejecting

The Institute of Contemporary Psychoanalysis, Los Angeles, California, USA

Correspondence to Dr Roberto D'Angelo, The Institute of Contemporary Psychoanalysis, Los Angeles 90064, California, USA; roberto@robertodangelo.com of his gender identification. Phoenix's gender identity is the starting point, the immutable and irreducible bedrock, from which this treatment journey begins. The key question is: how can we make Phoenix's body align with who they feel they are?

This immediately raises serious questions about the ethics of using a risky somatic intervention ${ }^{5} 6$ based on an unsubstantiated theory. I argue instead that how Phoenix experiences their gender is a point in time along the complex, non-linear and evolving journey that is their life. Phoenix's non-binary identity has a history and a formative context. It is an emergent phenomenon that arises at the intersection of a multitude of interacting systems and factors, including developmental, relational, biological, interpersonal, family context, social, economic and political systems. The aim of treatment, as I see it, is to understand how Phoenix came to feel that they are in the wrong body, or that their developing body will become the wrong body.

Although this approach may sound radical, it is not: it incorporates the systemic, psychodynamic and biopsychosocial approaches that psychiatry has successfully drawn on for decades to understand and ameliorate emotional suffering. The authors are proposing patient care that breaks with this tradition. With its narrow focus on gender identity as concrete, the clinicians and ethicists effectively ignore or even erase the complexity of Phoenix's lived history and the context within their gender distress is constituted. The paper is striking for the absence of any sense of Phoenix, the person, even for a hypothetical case. Phoenix has effectively been reduced to a diagnosis or a gender identity to be treated. The reification of Phoenix's non-binary identity effectively erases all personal meaning, the impact of the relational context and the sociopolitical surround. It constitutes a decontextualisation and dehumanisation, which is arguably profoundly unethical. ${ }^{7}$

Who is Phoenix? We know nothing about how and when Phoenix came to identify as non-binary or what being non-binary, male or female means to them, beyond how they would like to appear. How did Phoenix come to feel distressed by the potential of having an adult, sexed body and what does sexuality mean to them? What influences formed Phoenix's notions of gender: the family, peers, the culture, social media? Does Phoenix feel constrained by narrow definitions of what it means to be male or female, or by how gender is regulated sociopolitically? What possibilities does being a non-binary person make available that would not be available to them as a sexed adult, and why? How do Phoenix's erotic life, fantasies and sexual orientation relate to the desire to have no secondary sex characteristics?

We are also told nothing about Phoenix's relational and developmental history. How does the family function? What identifications with parents and significant others did Phoenix form? Is there a history of trauma or abuse? What unconscious processes are going on in the family? Does one of the parents not want Phoenix to grow up? Is there a family problem which Phoenix's identification helps to manage? Does Phoenix have interpersonal difficulties and what is the interpersonal function of asserting a non-binary identity? Is it a way of asserting separateness and independence, or is it a way of hiding and feeling less vulnerable? Does Phoenix see a non-binary identity as a solution to emotional pain, the causes of which Phoenix may not yet have considered.

This kind of psychotherapeutic exploration can extend in all directions, illuminating whether the causes of Phoenix's suffering are more complex than they first appear. The aim is not to identify psychopathology or to convert, but to explore the origins and meaning of Phoenix's distress, and to facilitate a process of personal growth in which Phoenix will come to know themself and find new and creative ways to thrive. In contrast, medicalisation of Phoenix's distress constitutes an erasure of the inevitably complex sources of Phoenix's pain, effectively dissociated, forgotten, via the medical reconfiguration of the body. Is this an attempt to 'forget' or to erase a painful developmental history? Is Phoenix indeed 'out of time', disconnected from the past? From a perspective that considers the whole person in context, ongoing puberty blockade (OPD) constitutes a therapeutic abandonment. While gender-affirming medical intervention aspires to help the individual 
actualise their true self, it potentially forecloses authentic self-discovery if not preceded by a thoroughgoing psychological exploration. Hopefully, Phoenix will discover answers to the question 'Who is Phoenix?' that are more complex than 'non-binary'. Armed with deeper selfawareness, Phoenix will then be in the best position to decide whether OPD will indeed be liberating, or whether it will deprive Phoenix of true growth and freedom.

Correction notice This paper has been updated since first published to update author name 'Roberto D'Angelo'.

Funding The authors have not declared a specific grant for this research from any funding agency in the public, commercial or not-for-profit sectors.

Competing interests None declared.

Patient consent for publication Not required.

Provenance and peer review Commissioned; internally peer reviewed.

\section{(2) \\ OPEN ACCESS}

Open access This is an open access article distributed in accordance with the Creative Commons Attribution Non Commercial (CC BY-NC 4.0) license, which permits others to distribute, remix, adapt, build upon this work non-commercially, and license their derivative works on different terms, provided the original work is properly cited, appropriate credit is given, any changes made indicated, and the use is non-commercial. See: http://creativecommons.org/ licenses/by-nc/4.0/.

(c) Author(s) (or their employer(s)) 2020. Re-use permitted under CC BY-NC. No commercial re-use. See rights and permissions. Published by BMJ.

\section{(D) Check for updates}

To cite D'Angelo R. J Med Ethics 2020;46:753-754.

Received 19 August 2020

Accepted 19 August 2020

Published Online First 8 October 2020

\section{S Linked}

http://dx.doi.org/10.1136/medethics-2019-106012

J Med Ethics 2020;46:753-754

doi:10.1136/medethics-2020-106822

\section{REFERENCES}

1 Lemma A. Present without past: the disruption of temporal integration in a case of Transsexuality. Psychoanal Ing 2016;36(5):360-70.

2 Notini L, Earp BD, Gillam L, et al. Forever young? the ethics of ongoing puberty suppression for non-binary adults. J Med Ethics 2020;46:743-52.

3 Ehrensaft D. From gender identity disorder to gender identity creativity: true gender self child therapy. $J$ Homosex 2012;59(3):337-56.

4 Fausto-Sterling $\mathrm{A}$. The dynamic development of gender variability. J Homosex 2012;59(3):398-421.

5 Heneghan C, Jefferson T. Gender Affirming hormone in children and adolescents. BMJ EMB Spotlight 2019.

6 National Health Service. Treatment gender dysphoria, 2020. Available: https://www.nhs.uk/conditions/genderdysphoria/treatment/

7 D'Angelo R. Psychiatry and the ethical limits of gender affirming care. In: Moore M, Brunskell-Evans H, eds. Inventing transgender children and young people. Cambridge Scholars, 2019: 73-92. 